\title{
Influence of Mg content on the band alignment at $\mathrm{CdS} /(\mathrm{Zn}, \mathrm{Mg}) \mathrm{O}$ interfaces
}

Cite as: Appl. Phys. Lett. 87, 032101 (2005); https://doi.org/10.1063/1.1995951

Submitted: 21 March 2005 • Accepted: 02 June 2005 • Published Online: 11 July 2005

G. Venkata Rao, F. Säuberlich and A. Klein

\section{ARTICLES YOU MAY BE INTERESTED IN}

Emitter/absorber interface of CdTe solar cells

Journal of Applied Physics 119, 233104 (2016); https://doi.org/10.1063/1.4953820

$\mathrm{Cu}(\mathrm{In}, \mathrm{Ga}) \mathrm{Se}_{2}$ solar cells with controlled conduction band offset of window/Cu(In, $\mathrm{Ga}_{2} \mathrm{Se}_{2}$ layers Journal of Applied Physics 89, 8327 (2001); https://doi.org/10.1063/1.1366655

$\mathrm{Mg}_{\chi} \mathrm{Zn}_{1-\mathrm{x}} \mathrm{O}$ as a II-VI widegap semiconductor alloy

Applied Physics Letters 72, 2466 (1998); https://doi.org/10.1063/1.121384

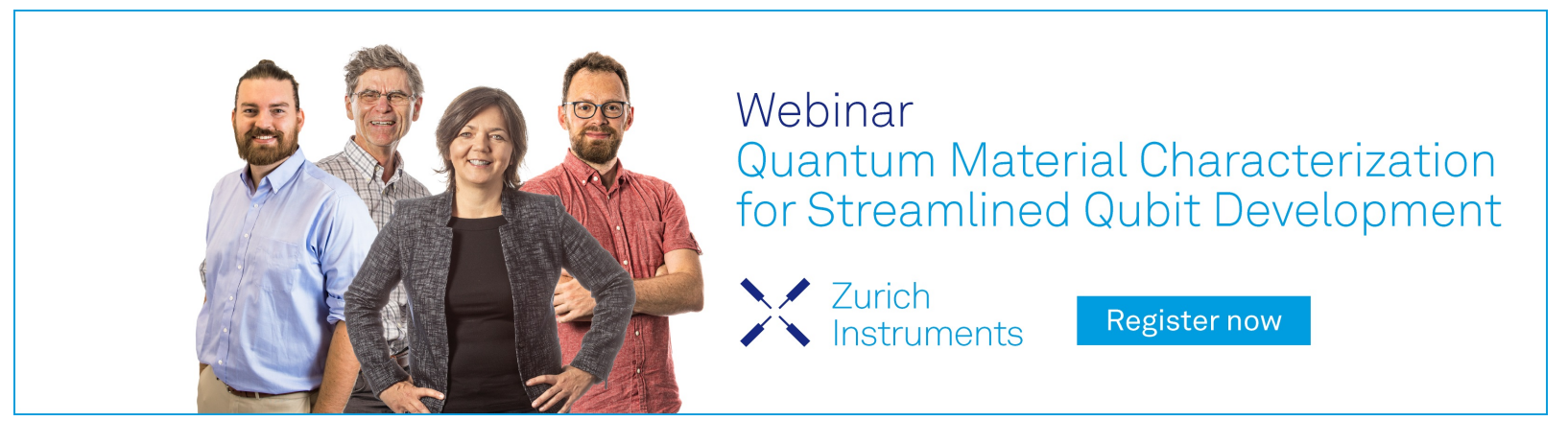




\title{
Influence of $\mathrm{Mg}$ content on the band alignment at $\mathrm{CdS} /(\mathrm{Zn}, \mathrm{Mg}) \mathrm{O}$ interfaces
}

\author{
G. Venkata Rao, F. Säuberlich, and A. Klein ${ }^{\text {a) }}$ \\ Darmstadt University of Technology, Institute of Materials Science, Surface Science Division, Petersenstrasse \\ 23, D-64287 Darmstadt, Germany
}

(Received 21 March 2005; accepted 2 June 2005; published online 11 July 2005)

\begin{abstract}
In this investigation, we studied electronic properties of the $\mathrm{CdS} / \mathrm{Zn}_{1-x} \mathrm{Mg}_{x} \mathrm{O}(x=0,0.15)$ interface using photoelectron spectroscopy. $\mathrm{ZnO}$ and $(\mathrm{Zn}, \mathrm{Mg}) \mathrm{O}$ films were deposited by magnetron sputtering from ceramic targets on thermally evaporated CdS. Valence-band offsets of $\Delta E_{V}=1.2 \pm 0.1 \mathrm{eV}$ are determined for both interfaces. The gap difference of $0.3 \mathrm{eV}$ between $\mathrm{ZnO}$ and $\mathrm{Zn}_{0.85} \mathrm{Mg}_{0.15} \mathrm{O}$ is therefore fully accommodated by a different conduction-band energy, which should be well suited for modulation doping in $\mathrm{ZnO} /(\mathrm{Zn}, \mathrm{Mg}) \mathrm{O}$ heterostructures. (C) 2005 American Institute of Physics. [DOI: $10.1063 / 1.1995951]$
\end{abstract}

Transparent conducting oxides play a critical role as a contact in numerous optoelectronic devices including solar cells and display technology. ${ }^{1} \mathrm{ZnO}$, e.g., has a direct band gap of $3.3 \mathrm{eV}$ and can be highly doped $n$-type achieving electrical resistivities as low as $2 \times 10^{-4} \Omega \mathrm{cm}$ (Ref. 2). The high conductivity is obtained by a high carrier density, which on the other hand leads to a reduction of the transparency in the near infrared region due to free-carrier absorption. ${ }^{1}$ Since the electron mobility in the highly doped materials is limited by charged impurity scattering, an increase of conductivity by increased carrier concentration is always accompanied by a reduction of the mobility, thus leading to a fundamental limitation of electrical properties. ${ }^{2}$ These limits might possibly be overcome by modulation doping. ${ }^{3}$

In order to apply the modulation doping technique to $\mathrm{ZnO}$-based thin films, control of the energy gap and carrier concentration is required. Recently $(\mathrm{Zn}, \mathrm{Mg}) \mathrm{O}$ alloys have been synthesized because $(\mathrm{Zn}, \mathrm{Mg}) \mathrm{O}$ has a larger band gap than $\mathrm{ZnO}$ (Refs. 4-9). Successful modulation doping of electrons in $\mathrm{ZnO}$ requires that $(\mathrm{Zn}, \mathrm{Mg}) \mathrm{O}$ has a higher conduction-band edge in contact with $\mathrm{ZnO}$. So far, the conduction-band discontinuity between $\mathrm{ZnO}$ and $(\mathrm{Zn}, \mathrm{Mg}) \mathrm{O}$ has not been measured directly, for instance, by XPS. An estimate based on the common anion rule suggests a negligible valence-band offset. ${ }^{10}$ However, interface dipoles and the shallow $d$ levels also affect the band-edge energies in II-VI compounds ${ }^{11,12}$ and a band alignment between $\mathrm{ZnO}$ and $(\mathrm{Zn}, \mathrm{Mg}) \mathrm{O}$ can thus not be predicted easily. Based on photoluminescence measurements of $\mathrm{ZnO} / \mathrm{Zn}_{0.8} \mathrm{Mg}_{0.2} \mathrm{O}$ superlattices, Ohtomo et al. suggested $\Delta E_{C} / \Delta E_{V} \sim 9$ (Ref. 13), while a larger valence-band offset $\left(\Delta E_{C} / \Delta E_{V} \sim 65 / 35\right)$ is suggested by Coli and Bajaj from an analysis of exciton binding energies in $\mathrm{ZnO} / \mathrm{Zn}_{1-x} \mathrm{Mg}_{x} \mathrm{O} \quad(x=0.12,0.27)$ superlattices. $^{14}$

The valence-band offsets at semiconductor interfaces can be directly assessed using photoelectron spectroscopy. ${ }^{15}$ Unfortunately, this is not straightforward for the $\mathrm{ZnO} /(\mathrm{Zn}, \mathrm{Mg}) \mathrm{O}$ interface because of the identical elements in both compounds. We have therefore determined the band alignment indirectly by depositing $\mathrm{ZnO}$ and $(\mathrm{Zn}, \mathrm{Mg}) \mathrm{O}$ on identical substrates and assuming transitivity of band alignments. CdS has been selected as substrate material because it

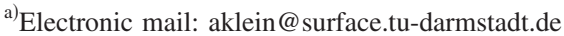

can be easily evaporated and its spectral features are well known in our group from a large number of experiments. In addition, the $\mathrm{CdS} / \mathrm{ZnO}$ interface is of particular importance for $\mathrm{Cu}(\mathrm{In}, \mathrm{Ga}) \mathrm{Se}_{2}$ thin-film solar cells, which have achieved energy conversion efficiencies above $19 \%{ }^{16}$

For the examination of interface properties of $\mathrm{CdS} / \mathrm{ZnO}$ and $\mathrm{CdS} /(\mathrm{Zn}, \mathrm{Mg}) \mathrm{O}$ using photoelectron spectroscopy, it is important that the sample does not leave an ultrahigh vacuum (UHV) environment during the entire experiment. Therefore, the experiment is carried out in an integrated UHV system which combines the preparation and the analysis in one vacuum system with a base pressure better than $10^{-7} \mathrm{~Pa}$. Evaporation of $\mathrm{CdS}$ is done from a homemade effusion cell from the compound. $\mathrm{ZnO}$ films were deposited by dc magnetron sputtering from a $\mathrm{ZnO}$ target and $(\mathrm{Zn}, \mathrm{Mg}) \mathrm{O}$ films were deposited by rf sputtering from a ( $\mathrm{Zn}, \mathrm{Mg}) \mathrm{O}$ target $(15 \mathrm{~mol} \% \mathrm{MgO})$ at $\sim 0.3 \mathrm{~W} / \mathrm{cm}^{2}$. Sputtering was performed in pure argon atmosphere at an Ar pressure of $0.5 \mathrm{~Pa}$ onto substrates held at room temperature. The pressure measurement was performed using a calibrated capacitance gauge. The band gap of a 700-nm-thick film deposited on a quartz substrate has been determined by optical spectroscopy as $3.6 \mathrm{eV}$, which is within the range given in literature for the nominal target composition. ${ }^{4,5,7}$

X-ray and UV photoelectron spectroscopy (XPS, UPS) measurements were carried out using a Physical Electronics PHI 5700 spectrometer system. As excitation for XPS monochromatic Al $K \alpha$ radiation $(h \nu=1486.6 \mathrm{eV})$ is used. The PHI system provides for XPS measurements and overall experimental resolution better than $400 \mathrm{meV}$ as determined by the gaussian broadening of the Fermi edge of a clean Ag sample. The spectrometer is calibrated at regular intervals by determining the core emission lines of copper $\left[B E\left(\mathrm{Cu} 2 p_{3 / 2}\right)\right.$ $=932.7 \mathrm{eV}]$, silver $\left[B E\left(\operatorname{Ag} 3 d_{5 / 2}\right)=368.3 \mathrm{eV}\right]$, and gold $\left[B E\left(\mathrm{Au} 4 f_{7 / 2}\right)=84.0 \mathrm{eV}\right]$. The $\mathrm{CdS} / \mathrm{ZnO}$ and $\mathrm{CdS} /(\mathrm{Zn}, \mathrm{Mg}) \mathrm{O}$ interfaces were examined by a stepwise deposition of the $\mathrm{ZnO}$ and $(\mathrm{Zn}, \mathrm{Mg}) \mathrm{O}$ on the $\mathrm{CdS}$ substrate with subsequent photoelectron spectroscopy measurements after each deposition step. For the determination of the exact binding energy of the measured emission lines the spectra are fitted with Voigt profile functions. The positions of the valence-band maxima were determined using linear extrapolation of the leading edge of the x-ray excited valence-band spectra. ${ }^{15}$ 

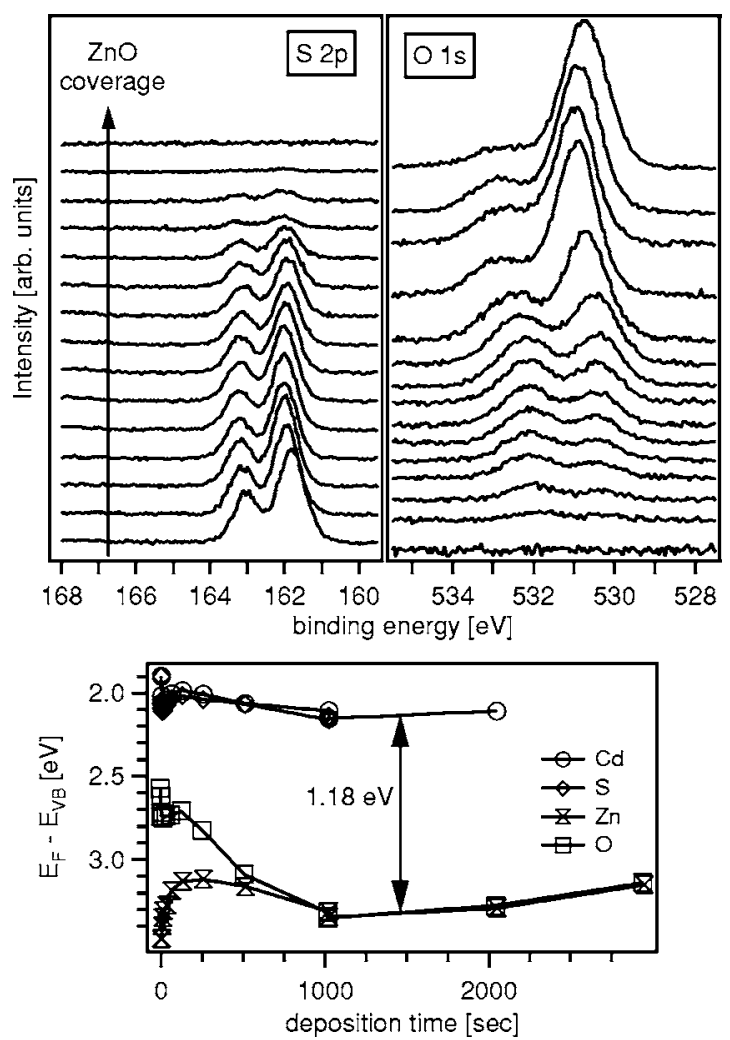

FIG. 1. S $2 p$ and O $1 s$ core-level spectra recorded during stepwise deposition of $\mathrm{ZnO}$ on CdS. The evolution of the valence-band maxima dependent on deposition time as derived from the core-level binding energies is shown at the bottom.

The core-level binding energies with respect to the valence-band maxima are determined as $B E_{V B}\left(\mathrm{Cd} 3 d_{5 / 2}\right)$ $=403.50 \mathrm{eV}$ and $B E_{V B}\left(\mathrm{~S} 2 p_{3 / 2}\right)=159.91 \mathrm{eV}$ for the $\mathrm{CdS}$ substrate; $B E_{V B}\left(\mathrm{Zn} 2 p_{3 / 2}\right)=1018.87 \mathrm{eV}$ and $B E_{V B}(\mathrm{O} 1 s)$ $=527.60 \mathrm{eV}$ for the thick $\mathrm{ZnO}$; and $B E_{V B}\left(\mathrm{Zn} 2 p_{3 / 2}\right)$ $=1018.93 \mathrm{eV}, B E_{V B}(\mathrm{Mg} 1 s)=1300.82 \mathrm{eV}$, and $B E_{V B}(\mathrm{O} 1 s)$ $=527.51 \mathrm{eV}$ for the thick $(\mathrm{Zn}, \mathrm{Mg}) \mathrm{O}$, respectively. A small uncertainty of $\sim 0.1 \mathrm{eV}$ can be obtained for these values by good statistics from a large number of films. Using the $B E_{V B}$ values, it is possible to determine the valence-band maximum of the film and the substrate for each deposition step by adding this value to the measured core-level binding energy.

Figure 1 shows the $\mathrm{O} 1 s$ and S $2 p$ core-level spectra obtained during stepwise deposition of $\mathrm{ZnO}$ on CdS. With increasing deposition time the $\mathrm{S} 2 p$ (and $\mathrm{Cd} 3 d$ ) intensities are gradually decreased and no change in spectral shape of the substrate levels is observed. In particular, there is no noticeable oxidation of the substrate. The $\mathrm{O} 1 s$ emission shows a two component structure, where the low binding-energy component originates from the $\mathrm{ZnO}$ compound. The high binding-energy component, which has been previously identified as a surface species, ${ }^{17}$ dominates at low coverage. We attribute this species mainly to a peroxolike compound $\left(\mathrm{ZnO}_{2}\right)$ at the surface of the growing $\mathrm{ZnO}$ film. ${ }^{21}$ Most likely the $\mathrm{ZnO}_{2}$ remains at the surface during film growth. The deposited films have the wurtzite $\mathrm{ZnO}$ structure as determined by XRD. The $\mathrm{ZnO}_{2}$ compound should therefore not affect the determined interface properties. It dominates at low coverage, since in the monolayer coverage regime no bulk $\mathrm{ZnO}$ phase can exist. The occurrence of the $\mathrm{ZnO}_{2}$ species indicates that the $\mathrm{Zn}$ atoms have only a poor ability to
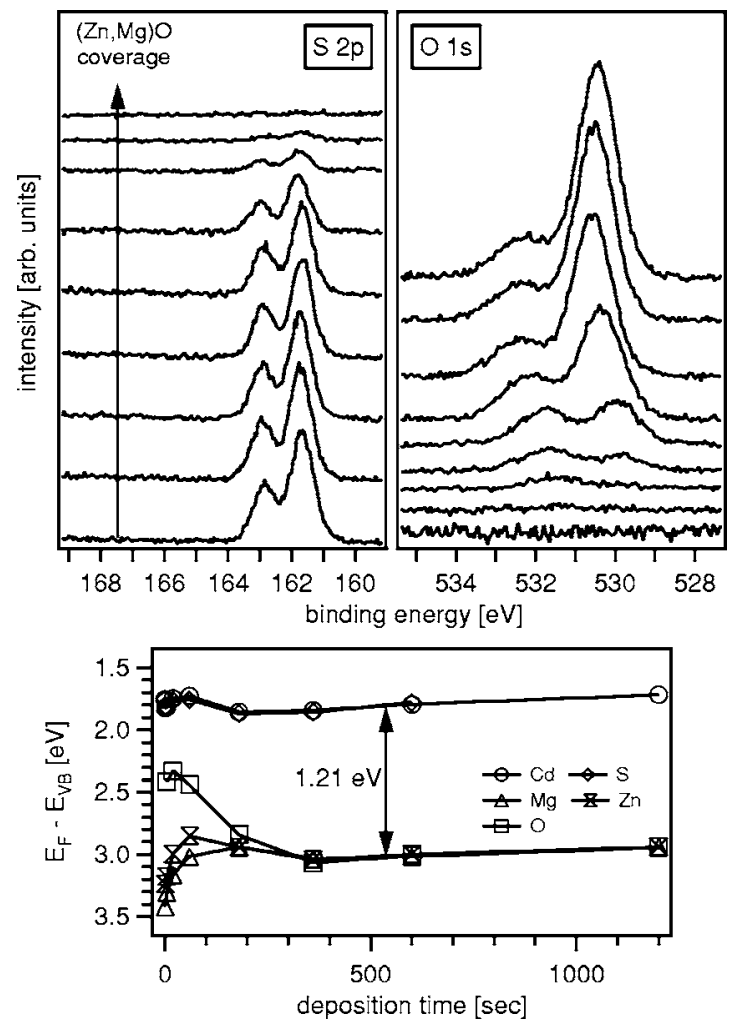

FIG. 2. S $2 p$ and $\mathrm{O} 1 s$ core-level spectra recorded during growth of $\mathrm{Zn}_{0.85} \mathrm{Mg}_{0.15} \mathrm{O}$ on CdS. The evolution of the valence-band maxima dependent on deposition time as derived from the core-level binding energies is shown at the bottom.

dissociate $\mathrm{O}_{2}$ molecules on the surface to form a $\mathrm{ZnO}$ compound.

The evolution of the core-level binding energies (see bottom of Fig. 1) also reflects the thickness-dependent composition of the film. Only after a deposition time of $1000 \mathrm{~s}$, corresponding to a $\mathrm{ZnO}$ film thickness of $\sim 3 \mathrm{~nm}$, the difference in binding energy of $\mathrm{Zn} 2 p$ and $\mathrm{O} 1 s$ levels has reached its bulk value, which is indicated by the merging of the two valence-band maxima curves derived from the $\mathrm{Zn} 2 p$ and $\mathrm{O} 1 s$ levels. For higher coverage it can be assumed that the core-level binding energies reflect the valence-band maximum energy of the $\mathrm{ZnO}$ film. From this point, they shift in parallel to the CdS substrate binding energies, allowing for a reliable determination of the valence-band offset, as indicated in the lower part of Fig. 1. The value of $\Delta E_{V}$ $=1.18 \pm 0.1 \mathrm{eV}$ is in good agreement with other determinations of the band offset at this interface. ${ }^{17-19}$

Figure 2 shows the $\mathrm{O} 1 s$ and S $2 p$ spectra obtained during stepwise deposition of $(\mathrm{Zn}, \mathrm{Mg}) \mathrm{O}$ on $\mathrm{CdS}$. The behavior of the core levels is completely analogous to those obtained during preparation of the $\mathrm{CdS} / \mathrm{ZnO}$ interface. Again no oxidation of the substrate is observed. The $\mathrm{O} 1 \mathrm{~s}$ level also shows a two-component structure, where the high bindingenergy component dominates the emission at low coverage. At higher coverage, the substrate and overlayer binding energies show parallel shifts (see bottom of Fig. 2). A valenceband offset of $\Delta E_{V}=1.21 \pm 0.1 \mathrm{eV}$ is derived.

The presented results indicate that the valence-band offset at the CdS $/ \mathrm{Zn}_{1-x} \mathrm{Mg}_{x} \mathrm{O}$ does not change for $x \leqslant 0.15$. The resulting energy-band diagrams for the two investigated interfaces are presented in Fig. 3. Bulk values for the band gaps are taken to indicate the conduction-band position. The 


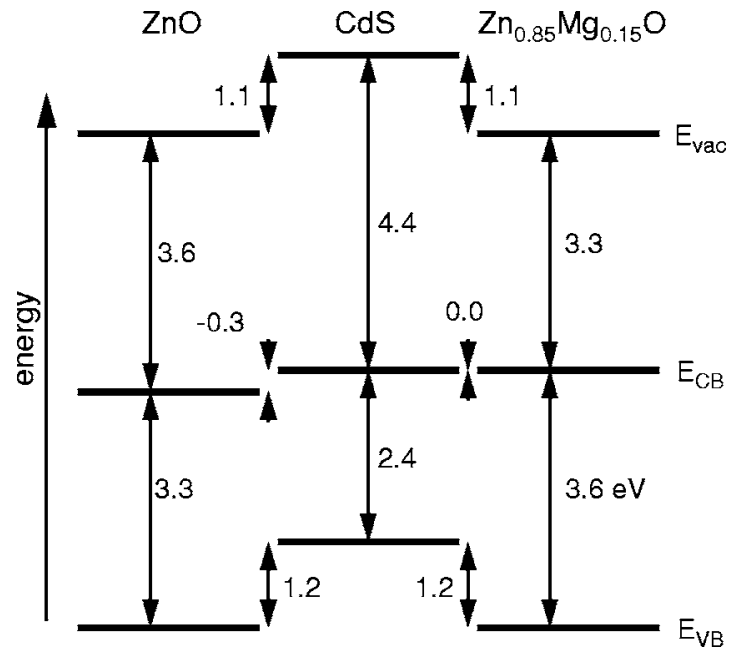

FIG. 3. Band alignment at $\mathrm{CdS} / \mathrm{ZnO}$ and $\mathrm{CdS} / \mathrm{Zn}_{0.85} \mathrm{Mg}_{0.15} \mathrm{O}$ interfaces as determined by the presented experiments. All values are given in electronvolts.

vacuum energy is derived from ionization potential measurements using ultraviolet photoelectron spectroscopy. Increasing the $\mathrm{Mg}$ content mainly affects the conduction-band offset as suggested by the common anion rule. The reduced $d$-metal contribution to the valence bands seems to have a minor effect on the band alignment, at least for low Mg contents.

Assuming transitivity of band alignment, which is typically fulfilled for interfaces of II-VI compounds, ${ }^{20}$ it is possible to give a value for the valence-band offset between $\mathrm{ZnO}$ and $\mathrm{Zn}_{0.85} \mathrm{Mg}_{0.15} \mathrm{O}$. The negligible valence-band maximum difference indicates a large offset ratio $\Delta E_{C} / \Delta E_{V}$, in agreement with the optical measurements of Ohtomo et al. ${ }^{13}$

In summary, we have presented an experimental determination of the band alignment between $\mathrm{CdS}$ and sputterdeposited $\mathrm{ZnO}$ and $\mathrm{Zn}_{0.85} \mathrm{Mg}_{0.15} \mathrm{O}$ films using photoelectron spectroscopy with in situ sample preparation. The valenceband offset at both interfaces is determined as $\Delta E_{V}$ $=1.2 \pm 0.1 \mathrm{eV}$. The difference in band gap of $0.3 \mathrm{eV}$ is therefore solely accommodated by different conduction-band offsets, allowing for modification of electron transport across the interface by adjusting the $\mathrm{Mg}$ content in $\mathrm{Zn}_{1-x} \mathrm{Mg}_{x} \mathrm{O}$. Assuming transitivity of band alignment our measurements can be considered as an experimental determination of the valence-band offset at the $\mathrm{ZnO} / \mathrm{Zn}_{1-x} \mathrm{Mg}_{x} \mathrm{O}$ interface. According to our results, $\mathrm{ZnO} / \mathrm{Zn}_{1-x} \mathrm{Mg}_{x} \mathrm{O}: \mathrm{Al}$ heterostructures should be well suited for modulation doping of electrons in $\mathrm{ZnO}$.

This work is supported by the Bundesministerium für Bildung \& Forschung (Grant No. 01SF0034) within the network "ZnO for thin film photovoltaics."

${ }^{1}$ H. L. Hartnagel, A. L. Dawar, A. K. Jain, and C. Jagadish, Semiconducting Transparent Thin Films (IOP, Bristol, 1995).

${ }^{2}$ K. Ellmer, J. Phys. D 34, 3097 (2001).

${ }^{3}$ R. Dingle, H. L. Störmer, A. C. Gossard, and W. Wiegmann, Appl. Phys. Lett. 33, 665 (1978).

${ }^{4}$ A. Ohtomo, M. Kawasaki, T. Koida, K. Masubuchi, H. Koinuma, Y. Sakurai, Y. Yoshida, T. Yasuda, and Y. Segawa, Appl. Phys. Lett. 72, 2466 (1998).

${ }^{5}$ T. Minemoto, T. Negami, S. Nishiwaki, H. Takakura, and Y. Hamakawa, Thin Solid Films 372, 173 (2000).

${ }^{6}$ S. Choopun, R. D. Vispute, W. Yang, R. P. Sharma, and T. Venkatesan, Appl. Phys. Lett. 80, 1529 (2002).

${ }^{7}$ R. Schmidt, B. Rheinländer, M. Schubert, D. Spemann, T. Butz, J. Lenzner, E. M. Kaidashev, M. Lorenz, A. Rahm, H. C. Semmelhack, and M. Grundmann, Appl. Phys. Lett. 82, 2260 (2003).

${ }^{8}$ N. B. Chen, H. W. Wu, D. J. Qiu, T. N. Xu, J. Chen, and W. Z. Shen, J. Phys.: Condens. Matter 16, 2973 (2004).

${ }^{9}$ B. P. Zhang, N. T. Binh, K. Wakatsuki, C. Y. Liu, and Y. Segawa, Appl. Phys. Lett. 86, 032105 (2005).

${ }^{10}$ J. O. McCaldin, T. C. McGill, and C. A. Mead, Phys. Rev. Lett. 36, 56 (1976).

${ }^{11}$ S.-H. Wei and A. Zunger, Phys. Rev. Lett. 59, 144 (1987).

${ }^{12}$ S.-H. Wei and A. Zunger, Phys. Rev. B 37, 8958 (1988).

${ }^{13}$ A. Ohtomo, M. Kawasaki, I. Ohkubo, H. Koinuma, T. Yasuda, and Y. Segawa, Appl. Phys. Lett. 75, 980 (1999).

${ }^{14}$ G. Coli and K. K. Bajaj, Appl. Phys. Lett. 78, 2861 (2001).

${ }^{15}$ Heterojunction Band Discontinuities, edited by F. Capasso and G. Margaritondo (North-Holland, Amsterdam, 1987).

${ }^{16}$ K. Ramanathan, M. A. Contreras, C. L. Perkins, S. Asher, F. S. Hasoon, J. Keane, D. Young, M. Romero, W. Metzger, R. Noufi, J. Ward, and A. Duda, Prog. Photovoltaics 11, 225 (2003).

${ }^{17}$ F. Säuberlich, J. Fritsche, R. Hunger, and A. Klein, Thin Solid Films 431/432, 378 (2003).

${ }^{18}$ M. Ruckh, D. Schmid, and H. W. Schock, J. Appl. Phys. 76, 5945 (1994).

${ }^{19}$ L. Weinhardt, C. Heske, E. Umbach, T. P. Niesen, S. Visbeck, and F. Karg, Appl. Phys. Lett. 84, 3175 (2004).

${ }^{20}$ T. Schulmeyer, R. Hunger, M. Lebedev, W. Jaegermann, A. Klein, R. Kniese, and M. Powalla, Thin Solid Films 480-481, 110 (2005).

${ }^{21}$ The dominant gas phase species obtained from sputtering of the target are $\mathrm{Zn}$ and $\mathrm{O}_{2}$. $\mathrm{ZnO}$ is formed by reaction of $\mathrm{Zn}$ under dissociation of $\mathrm{O}_{2}$ on the surface.

This article may be downloaded for personal use only. Any other use requires prior permission of the author and AIP Publishing.

This article appeared in Appl. Phys. Lett. 87, 032101 (2005) and may be found at https://doi.org/10.1063/1.1995951.

Available under only the rights of use according to UrhG. 